\title{
Sistematização da tabuada em duas proposições de ensino ${ }^{1}$
}

DOI 10.26512/lc.v24i0.20109

Josélia Euzébio da Rosa ${ }^{2}$ Ediséia Suethe Faust Hobold ${ }^{3}$

\section{Resumo}

Investigamos o movimento de sistematização da tabuada proposta em dois livros didáticos do segundo ano do ensino fundamental, um brasileiro e outro russo. Constatamos que as duas proposições seguem movimentos distintos. $\mathrm{Na}$ brasileira, a tabuada surge a partir da observação das quantidades. A essência conceitual resulta da aparência externa dos agrupamentos, carente de análise nas relações que geram sua lógica interna. Na proposição russa, por sua vez, o ensino da tabuada contempla a inter-relação das significações aritméticas, algébricas e geométricas no movimento que envolve o geral, universal, particular e singular, a partir das relações entre grandezas discretas e contínuas.

Palavras-chave: Educação matemática. Proposições de ensino. Tabuada.

1 Fontes financiadoras: Conselho Nacional de Desenvolvimento Científico e Tecnológico - CNPq - Brasil e Fundação de Apoio à Pesquisa Científica e Tecnológica do Estado de Santa Catarina (FAPESC).

2 Doutora em Educação pela Universidade Federal do Paraná (UFPR).

3 Mestre em Educação pela Universidade do Sul de Santa Catarina (UNISUL). 


\section{Resumen}

Investigamos el movimiento de sistematización de la tabla de multiplicación propuesta en dos libros de textos del segundo año de la enseñanza primaria, un brasileño y otro ruso. Constatamos que las dos proposiciones siguen movimientos distintos. En la brasileña, la tabla de multiplicación surge desde la observación de las cuantidades. La esencia conceptual resulta de la apariencia externa de los agrupamientos, carente de análisis en las relaciones que generan su lógica interna. En la proposición rusa, a su vez, la enseñanza de la tabla de multiplicación contempla la inter-relación de las significaciones aritméticas, algebraicas y geométricas en el movimiento que involucra el general, universal, particular y singular, desde las relaciones entre grandezas discretas e continuas.

Palabras-clave: Educación Matemática. Proposiciones de enseñanza. Tabla de multiplicación.

\section{Abstract}

We have researched the movement of systematization of the multiplication table proposed in two textbooks for the second grade of elementary school, one Brazilian and another Russian. We have noticed that the two propositions follow different movements. In the Brazilian one, the multiplication table arises from the observation of quantities. The conceptual essence results from the external appearance of groups, and needs analysis of relations which generate its internal logic. In the Russian proposition, on the other hand, the teaching of multiplication table contemplates the interrelation of arithmetic, arithmetic and algebraic meanings in the movement that involves the general, universal, particular and singular from the relationships among discrete and continuous magnitudes.

Keywords: Mathematics Education. Teaching propositions. Multiplication table. 


\section{Résumé}

Nous avons étudié le mouvement de systématisation de la table de multiplication proposée dans deux manuels pour la deuxième année de l'école élémentaire, l'un brésilien et l'autre russe. Nous avons remarqué que les deux propositions suivent des mouvements différents. Dans le cas brésilien, la table de multiplication provient de l'observation des quantités. L'essence conceptuelle résulte de l'apparence extérieure des groupes et nécessite une analyse des relations qui génèrent sa logique interne. Dans la proposition russe, en revanche, l'enseignement de la table de multiplication envisage l'interrelation des significations arithmétiques, arithmétiques et algébriques dans le mouvement qui implique le général, I'universel, le particulier et le singulier des relations entre les grandeurs discrètes et continues.

Mots-clés: Enseignement des mathématiques. Propositions d'enseignement Table de multiplication.

\section{Introdução}

A Proposta Curricular da Rede Estadual de Educação do Estado de Santa Catarina, Brasil, anuncia-se sustentada nos fundamentos do materialismo histórico e dialético desde 1991. A partir de então, outros referencias de mesma origem epistemológica foram incorporados no referido documento, como a teoria histórico-cultural, teoria do ensino desenvolvimental e atividade orientadora de ensino. Na especificidade da matemática, a ênfase é para os princípios didáticos propostos por Davýdov (1982) e colaboradores.

Diante do que preconiza o currículo escolar catarinense, cumpre questionar: a proposição davydoviana, tal como preconiza a proposta curricular escolar, chega até a sala de aula? Em caso afirmativo, como chega? Quais livros didáticos de matemática são adotados pelos professores de escolas da rede estadual de ensino catarinense? Nos livros didáticos adotados pelos professores estão objetivados os princípios didáticos propostos por Davýdov, como recomenda a Proposta Curricular do Estado de Santa Catarina?

Vasily Vasilyevich Davýdov ${ }^{4}$, juntamente com colaboradores, elaborou uma proposição para o ensino de matemática fundamentada na lógica dialética. Davýdov nasceu em Moscou, Rússia, no ano de 1930 e faleceu em 1998 aos 68 anos. Com um projeto de

4 No decorrer do texto, utilizaremos a grafia Davýdov. Porém, quando se tratar de referência a alguma obra, utilizaremos a grafia apresentada na mesma: Davýdov e Davídov. 
formação de um novo homem na sociedade socialista soviética Davýdov almejava que a escola "ensinasse os alunos a orientarem-se com autonomia na informação científica e em qualquer outra esfera do conhecimento" (Libâneo \& Freitas, 2013, p. 315). Este foi seu objetivo de pesquisa no decorrer de sua vida acadêmica na Rússia.

Suas investigações foram "fundamentadas na teoria histórico-cultural fundada por Vygostky e desenvolvida por Luria, Leontiev, Galperin, Elkonin, Zaporojets, entre outros colaboradores" (Libâneo \& Freitas, 2013, p. 315). No entanto, Davýdov foi o pesquisador da terceira geração dessa escola científica que mais se destacou em psicologia pedagógica (Libâneo \& Freitas, 2013; Rosa, 2012).

Durante sua vida acadêmica, Davýdov "teve como professores Leontiev, Luria, Rubinstein, Galperin, Zaporozhets, Sokolov, Talizina, Elkonin entre outros" (Libâneo \& Freitas, 2013, p. 318). Tornou-se colaborador de seus professores em estudos e pesquisas, dentre eles, destacam-se Galperin, seu primeiro orientador; Elkonin, companheiro de pesquisas nas escolas de Moscou e llienkov, amigo e parceiro de discussões filosóficas. Estes três pesquisadores integram a nossa referência na investigação apresentada.

No Instituto de Psicologia, nas décadas de 1970 e 1980, e eram realizadas investigações experimentais sobre as relações entre educação e desenvolvimento por dois grupos de pesquisadores: o de Zankov, na Escola Experimental n 17 em Kharkov, Ucrânia; e o de Elkonin e Davýdov, na Rússia. No entanto, foram as pesquisas do segundo grupo, desenvolvidas na Escola Experimental n 91, nas décadas de 1970 e 1980, que propiciaram a formulação do Ensino Desenvolvimental (Libâneo \& Freitas, 2013).

Por mais de 20 anos (décadas de 1970 e 1980) foram realizadas pesquisas sobre formação do pensamento teórico dos estudantes de nacionalidade russa. Essas investigações ocorreram, principalmente, no ensino fundamental nas disciplinas de matemática, língua russa, literatura, ciências, artes plásticas e música. Na década de 1980 as pesquisas sobre o ensino desenvolvimental estenderam-se para o ensino de $5^{\mathrm{a}}$ a $8^{\mathrm{a}}$ série.

Além disso, esse sistema é objeto de investigações "desenvolvidas em países como Ucrânia, Cazaquistão, Noruega, França, Alemanha, Holanda, Canadá, Japão [...] Estados Unidos" e Brasil (Rosa, 2012, p. 26). O ensino desenvolvimental também é adotado em uma escola particular de educação básica em Puebla, no México.

Davýdov e Elkonin, nas décadas de 1970 e 1980, na Rússia, detectaram que a atividade de estudo não estava presente nas escolas. Este fato levou-os a propor, em 1960, a elaboração de novos programas para o ensino fundamental. A principal mudança consistia no conteúdo e no método e, consequentemente, na metodologia de ensino. Foi no trabalho realizado nesse laboratório que surgiu a hipótese de investigação davydoviana, na qual "as crianças pequenas podem desenvolver o pensamento teórico por meio da assimilação de conhecimento teórico” (Libâneo \& Freitas, 2013, p. 320). 
Essa investigação vinha de encontro ao ensino desenvolvido nas escolas russas da época, nas quais, o que vigorava era o tradicional. Vale esclarecer que o ensino tradicional, para Davýdov, é diferente do que habitualmente se compreende no Brasil. Em nosso país, comumente se entende por ensino tradicional aquele em que $o$ professor é o detentor do conhecimento e o aluno é sujeito passivo que recebe esse conhecimento transmitido pelo primeiro. Para Davýdov, o ensino tradicional é aquele que promove, preponderantemente, o pensamento empírico.

No ensino tradicional, tal como interpreta Davýdov (1982), os objetos são apreendidos, primeiro, pela aparência. São comparados com outros objetos a fim de identificar as características comuns para classificá-los e, por fim, nomeá-los (generalização empírica e abstração verbal empírica). Este tipo de ensino contempla apenas os conhecimentos empíricos e se aproxima da maioria das práticas educacionais tradicionalmente desenvolvidas nas escolas brasileiras (Hobold \& Rosa, 2017).

Neste contexto de reflexões, temos como hipótese que os livros didáticos de matemática adotados por professores de escolas da rede estadual de ensino catarinense mais se distanciam do que se aproximam da proposição davydoviana de ensino. A fim de confirmar ou refutar tal hipótese, procedemos uma análise comparativa entre duas coleções de livros didáticos, uma organizada por Davýdov e colaboradores, e aquela adotada por professores da rede estadual de ensino catarinense. Tomamos como foco de análise, em ambas coleções, as situações que propõem a sistematização da tabuada.

No que se refere à proposição brasileira, consideramos a coleção Porta Aberta dos autores Centurión, Scala e Rodrigues (2011). Tal obra era a mais utilizada pelos professores das escolas estaduais dos municípios que constituíam a extinta $36^{a}$ Gerência Regional de Educação, com sede em Braço do Norte, Santa Catarina (Hobold, 2014).

Quanto à proposição russa buscamos, no interior do sistema de ensino ElkoninDavýdov a referência de análise. Conforme adiantamos, Davýdov e colaboradores como Gorbov, Mikulina e Savieliev, sistematizaram uma proposta para o ensino de matemática e a publicaram em livros didáticos (Davýdov et al., 2012) e manuais de orientação ao professor (Gorbov, Mikulina, \& Savieliev, 2009).

Com o objetivo de analisar as situações relacionadas ao processo de sistematização da tabuada em ambas proposições desenvolvemos as seguintes ações de pesquisa:

1. Estudo de todo o material didático.

2. Seleção das situações referentes à sistematização da tabuada.

3. Estudo das respectivas bases teórico-metodológicas. 
Tais ações de pesquisa foram desenvolvidas no contexto de dois grupos de pesquisa que constituem um coletivo de formação. Trata-se Grupo de Pesquisa Teoria do Ensino Desenvolvimental na Educação Matemática (TedMat/UNISUL) e o Grupo de Pesquisa em Educação Matemática: uma Abordagem Histórico-Cultural (GPEMAHC/UNESC). Ambos constituem a unidade catarinense da Rede Nacional de Grupos de Pesquisa, do Grupo de Estudos e Pesquisas sobre a Atividade Pedagógica (GEPAPE/USP).

Nesse coletivo de formação, sustentamos a pesquisa no materialismo histórico e dialético. Com base filosófica no marxismo, o referido método consiste na busca por explicações coerentes, lógicas e racionais para o objeto investigado (Triviños, 1987). A dialética materialista e suas categorias têm a "função de método do conhecimento científico" (Kopnin, 1978, p. 109). Para Kosik (1995), a dialética materialista é "o método do desenvolvimento e da explicitação dos fenômenos culturais partindo da atividade prática objetiva do homem histórico" (p. 39).

Em concernência com o método, orientamo-nos no processo de realização da presente investigação em três pares de categorias que consideramos fundamentais no processo do conhecer: abstrato/concreto, geral/particular, universal/singular. Cada uma dessas categorias "revela uma determinada face das complexas contradições da realidade em seu movimento e somente a análise de todas essas faces, em síntese, pode reproduzir no pensamento a representação do objeto" (Rosental, 1962, p. 299).

Os referidos pares de categorias lógicas apresentam contradições que estão em constante movimento. Algumas categorias "se transformam em outras em consonância com o desenvolvimento das propriedades e relações dos fenômenos e processos reais, da realidade objetiva, propriedades e fenômenos refletidos nas contradições principais" (Rosental, 1962, p. 277). Isto significa afirmar que as contradições existentes entre as categorias no processo de desenvolvimento do conhecimento transformamse em outras.

De acordo com Ilienkov (2006) "essas categorias, como contrários, passam de uma para a outra no processo de cognição: o abstrato torna-se concreto e o concreto em abstrato" (p. 153) dependendo do nível em que o investigador chegou no processo de análise.

O concreto e o abstrato, de acordo com Rosental (1960, p. 324), são de grande importância para a compreensão da "essência do conhecimento". A essência é constituída na elevação do singular para o universal, do fenômeno para a lei. Um dos aspectos desse movimento "é a relação entre o abstrato e o concreto [...]"(Ilienkov, 2006, p. 151), o caminho que leva do mundo objetivo para a abstração.

O abstrato "é uma parte de um todo, extraída dele e isolada do todo, nexo e interação com os demais aspectos e relações do todo. É esta característica principal que faz da abstração o contrário do concreto" (Ilienkov, 2006, p. 152). A abstração inicial, substancial, expressa a essência do objeto concreto. 
[...] Essência é a conexão interna que, como fonte única, como base genética, determina todas as outras especificidades particulares do todo. Trata-se de conexões objetivas, as que em sua dissociação e manifestação asseguram a unidade dos aspectos do todo, isto é, dão ao objeto um caráter concreto. Neste sentido, a essência é a determinação universal do objeto. Por isso a abstração geneticamente inicial, substancial, expressa a essência do objeto concreto. [...] (Davídov, 1988, p. 147, tradução nossa).

O universal, como essência, aparece em forma de lei. Assim, lei e essência são conceitos de mesma ordem, ou melhor, de mesmo grau. O conhecimento não passa, imediatamente, "do sensorial-concreto ao concreto pensado. Esse caminho, como todos os outros, é complexo e contraditório. Para atingir a concreticidade autêntica, o conhecimento perde temporariamente a concreticidade em geral e passa ao seu próprio oposto: ao abstrato" (Kopnin, 1978, p. 158).

Por outro lado, "o concreto, no conhecimento, é um todo reproduzido no pensar; [...] é a realidade apreendida em carne e osso; o abstrato é no âmbito dos aspectos, propriedades, características, traços, objetos, etc., singulares isolados do todo" (Ilienkov, 2006, p. 153). O concreto, no pensamento,

[...] é o conhecimento mais profundo e substancial dos fenômenos da realidade, pois reflete com o seu conteúdo, não as definibilidades exteriores do objeto em sua relação imediata, acessível à contemplação viva, mas diversos aspectos substanciais, conexões, relações em sua vinculação interna necessária (Kopnin, 1978, p. 162, grifos do autor).

A contradição entre abstrato e concreto que ocorre no pensamento, "expressa a contradição mais ampla existente entre o universal e o singular, entre a lei e o fenômeno, entre a essência e a forma em que esta se manifesta". A abstração geneticamente inicial expressa a essência, "porém nem sempre o faz por completo" (Ilienkov, 2006, p. 169). A abstração inicial reflete "a essência, a lei dos fenômenos, de maneira abstrata, em seu aspecto puro" (Ilienkov, 2006, p. 169).

Deste modo, na especificidade da investigação ora relatada, o concreto real, o ponto de partida, é o material didático referente à duas proposições para o ensino da tabuada. Em outras palavras, trata-se da materialização do nosso objeto de estudo. Essa foi a realidade objetiva, concreta, na qual iniciamos o processo do conhecer. Como ensina Ilienkov (2006, p. 159), "o ponto de partida do conhecimento é a realidade objetiva, concreta. O pensamento realiza todas suas operações com esta realidade, com o material da mesma".

Porém, conforme refletimos anteriormente, o concreto, em nível sensorial, enquanto ponto de partida, não explicita, externamente, as conexões internas. Estas somente são reveladas no processo de conhecer a realidade. A realidade que objetivamos refletir no presente artigo refere-se a duas proposições distintas para o ensino da tabuada, 
uma brasileira e outra russa, que resultaram da atividade prática objetiva do homem histórico. Tais proposições, objetivadas em materiais didáticos (livros didáticos e manuais de orientações), constituíram o concreto ponto de partida.

Para atender ao objetivo proposto, inicialmente estudamos os livros didáticos e constatamos que a sistematização da tabuada, em ambas proposições inicia no segundo ano escolar (ensino fundamental I), razão pela qual optamos por esse livro. $\mathrm{Na}$ sequência, selecionamos as situações referentes à sistematização da tabuada e localizamos as respectivas orientações nos manuais de orientação ao professor.

Posteriormente, procedemos ao estudo das respectivas bases teórico-metodológicas para, a partir de então, analisarmos o movimento de sistematização da tabuada em ambas as proposições.

A partir das ações relatadas anteriormente, organizamos o presente artigo em duas seções. Foi necessária a apresentação das proposições em seções separadas porque elas imprimem movimentos conceituais distintos. A unificação poderia ofuscar o movimento característico em cada uma. A fim de garantir a interconexão do referencial teórico com os dados de pesquisa, ele é apresentado no decorrer da análise, conforme segue.

\section{Sistematização da tabuada na proposição brasileira}

Ao analisar o movimento de sistematização da tabuada apresentado no livro do segundo ano da coleção de livros didáticos mais utilizada pelos professores da extinta $36^{\text {a }}$ GERED de Braço do Norte-SC (Hobold, 2014), detectamos resultados semelhantes àqueles obtidos por Davýdov (1982), ao analisar as proposições para o ensino de matemática em seu país, no século XX. Davýdov (1982) denominou o ensino predominante em sua época, na Rússia, de tradicional, por se sustentar nos fundamentos da lógica formal, na teoria empírica de abstração, generalização e formação de conceito.

Uma das finalidades principais do ensino tradicional consiste em inculcar nas crianças generalizações, abstrações e conceitos empíricos coincidentes com a descrição da lógica formal tradicional (Davýdov, 1982). Para o autor em referência, os livros didáticos do ensino tradicional são elaborados de tal forma que objetivam a referida finalidade.

Nos séculos XVIII e XIX, de acordo com Davýdov (1982), a teoria empírica passou a integrar o conteúdo escolar, e a lógica formal exerceu papel fundamental sobre a psicologia e a didática. Em quase todo o século XIX as ideias psicológicas sobre o pensamento desenvolveram-se fundamentadas na lógica formal e persistem até 
os tempos atuais no Brasil (Rosa, 2012). Tal lógica apresenta uma teoria original e é adotada como método de conhecimento (Kopnin, 1978).

No modo de organização do ensino fundamentado na lógica formal tradicional, os conceitos são elaborados pelos estudantes por meio da observação das características externas de um grupo de objetos sensorialmente dados aos órgãos dos sentidos. A análise consiste em abstrair algumas características gerais e substanciais imprescindíveis aos objetos. Consequentemente, o conceito é elaborado com base na aparência externa, nas características comuns aos vários objetos observados externamente.

Os manuais da lógica formal, de acordo com Chelpanov (1946, como citado em Davýdov, 1982), indicam que os objetos circundantes ao homem possuem diversas propriedades como, por exemplo, qualidades, medidas e estados que se encontram em diferentes relações (espaciais, temporais, causais). Em meio a uma multiplicidade de propriedades e relações concretas (dadas pela aparência externa), os objetos podem apresentar semelhanças entre si em alguns aspectos e diferenciarem-se em outros.

Assim, a identificação das características externas dos objetos é uma particularidade da lógica formal tradicional. Nela, o homem destaca seus indícios ao formar ideias sobre os aspectos dos objetos. Todo objeto possui uma série de propriedades que são comuns com as de outros objetos e diversas propriedades pelas quais se distingue dos demais.

As ideias concernentes a todas essas propriedades denominam-se indícios. $O$ procedimento lógico de comparação é efetuado para estabelecer as diferenças e semelhanças entre os objetos. O processo de conhecimento de qualquer objeto inicia quando o comparamos à outros. Pela comparação é possível diferenciar ou estabelecer semelhanças entre eles.

No entanto, de acordo com as propriedades similares ou comuns, um objeto pode se relacionar em uma classe geral com outros objetos. Em outras palavras, segundo certos indícios comuns (iguais), os objetos singulares podem se associar em determinado conjunto ou classe.

Na lógica formal tradicional, atinge-se o conceito ao se designar os indícios comuns, substanciais, por meio de palavras (abstração verbal). Neste ponto de vista, a definição de conceito é a forma pela qual se refletem as características essenciais dos objetos (Rosental, 1962). A essência está nas características comuns, imprescindíveis aos vários objetos de determinado grupo que garantem a elaboração do conceito. Porém, estas características são dadas diretamente aos órgãos dos sentidos. Não há uma análise mais profunda das relações internas que o conceito apresenta. Deste modo, a lógica do conceito é a "[...] lógica da essência dada a partir da aparência externa do objeto" (Lefebvre, 1991, p. 142).

Esta lógica está subjacente à proposição brasileira analisada, na qual o conceito de multiplicação, base para a tabuada, é abordado a partir de diferentes situações em que 
a multiplicação pode ser utilizada, tais como adição de parcelas iguais, organização retangular, proporcionalidade, combinação, padrões geométricos, o dobro, triplo, quádruplo, entre outros. Estas características são base para separar os objetos em classes, conforme a ilustração 1.

Ilustração 1 - Apresentação do conceito de multiplicação no livro do segundo ano

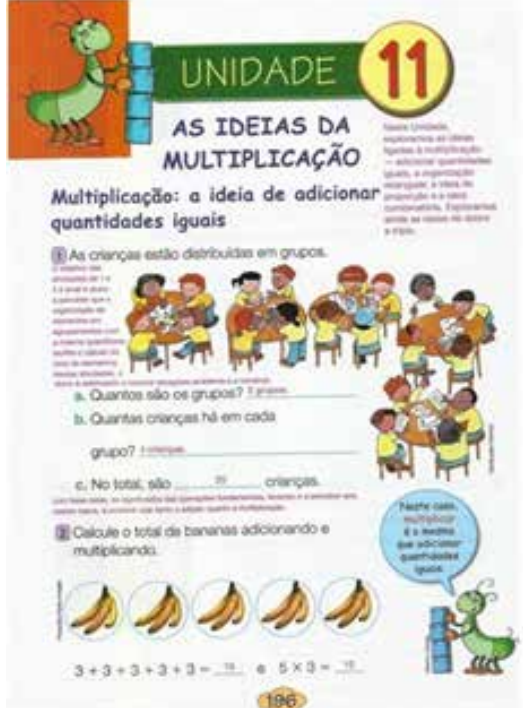

Fonte: Centurión et al. (2011, p. 196).

As representações propostas (Ilustração 1) propiciam a percepção das quantidades a serem operadas: cinco grupos compostos pelo mesmo número de unidades, seja de crianças ( 4 em cada grupo) ou de bananas ( 3 em cada grupo). Logo, a generalização consiste em: quando houver cinco (5) agrupamentos, compostos pelo mesmo número de unidades, o total será: $4+4+4+4+4=20,3+3+3+3+3=15$, e assim sucessivamente. Para finalizar a página introdutória, há um balão com o seguinte enunciado: "Nesse caso, multiplicar é o mesmo que adicionar quantidades iguais" (Centurión et al., 2011, p. 196).

O conceito é expresso por palavras abstraídas de percepções e representações. Em outras palavras, resulta de uma síntese de percepções e representações de fenômenos e objetos homogêneos. Deste modo, o conceito e as características essenciais dos objetos são extraídos das relações externamente dadas aos órgãos dos sentidos.

Os procedimentos metodológicos apresentados no exemplo anterior reproduzem a generalização compatível ao ensino tradicional que, apoiando-se nas observações, refletem nas representações as propriedades externas dos objetos. "Permanece em um grau inferior do conhecimento, embora se trate de um grau válido, envolvido e 
implicado nos graus superiores" (Lefebvre, 1991, p. 143).

Por consequência, o processo de estudo dos conceitos, ao ter a lógica formal por base, traz uma intenção de generalização também empírica, marcada inclusive pela resolução de situações similares.

As figuras ilustrativas mudam ao longo do livro. No entanto, sua essência empírica continua: desenhar a mesma quantidade de objetos em cada grupo, adicionar as quantidades iguais e, finalmente, representar as ilustrações por meio da operação de multiplicação. A quantidade de grupos e o número total de figuras a serem desenhadas em cada grupo são definidos previamente, nos enunciados. O foco incide na determinação do número total de objetos em cada agrupamento, em detrimento da lógica interna que gera tal resultado.

No ensino tradicional, o professor utiliza o método comparativo para descrever as características comuns apresentadas em cada situação, ao final desse processo de generalização (Davýdov, 1982). Neste sentido, em cada situação conclui-se, por meio da comparação, que a adição de parcelas iguais pode ser representada por meio de outra operação: a multiplicação. O domínio desses procedimentos é um caso particular do processo de generalização, cujo resultado é o conceito de multiplicação.

Portanto, na perspectiva empírica, é indispensável variar as características insubstanciais dos conceitos, propriedades e fatos, mantendo constantes as características essenciais para que se formulem generalizações corretas, do ponto de vista da lógica formal tradicional. De acordo com Lefebvre (1991), as características são classificadas em dois grupos: o dos atributos essenciais ou indícios substanciais, e o grupo formado pelos atributos acidentais, insubstanciais.

Indícios substanciais são as propriedades comuns de certo grupo de objetos, atributos necessários e suficientes para distinguir o grupo dado dos demais. A determinação das características essenciais pressupõe destaque das propriedades comuns do grupo de objetos por meio da comparação entre eles, e da seleção daqueles considerados suficientes para diferenciar o grupo dado dos demais.

Com essa compreensão de apropriação e formulação do conceito, o livro didático do segundo ano apresenta, após a relação da operação de multiplicação com as ideias de organização retangular, proporcionalidade e análise combinatória, as tabelas de multiplicação/tabuadas (Ilustração 2): 
Ilustração 2 - Generalização da tabuada na proposição brasileira em análise

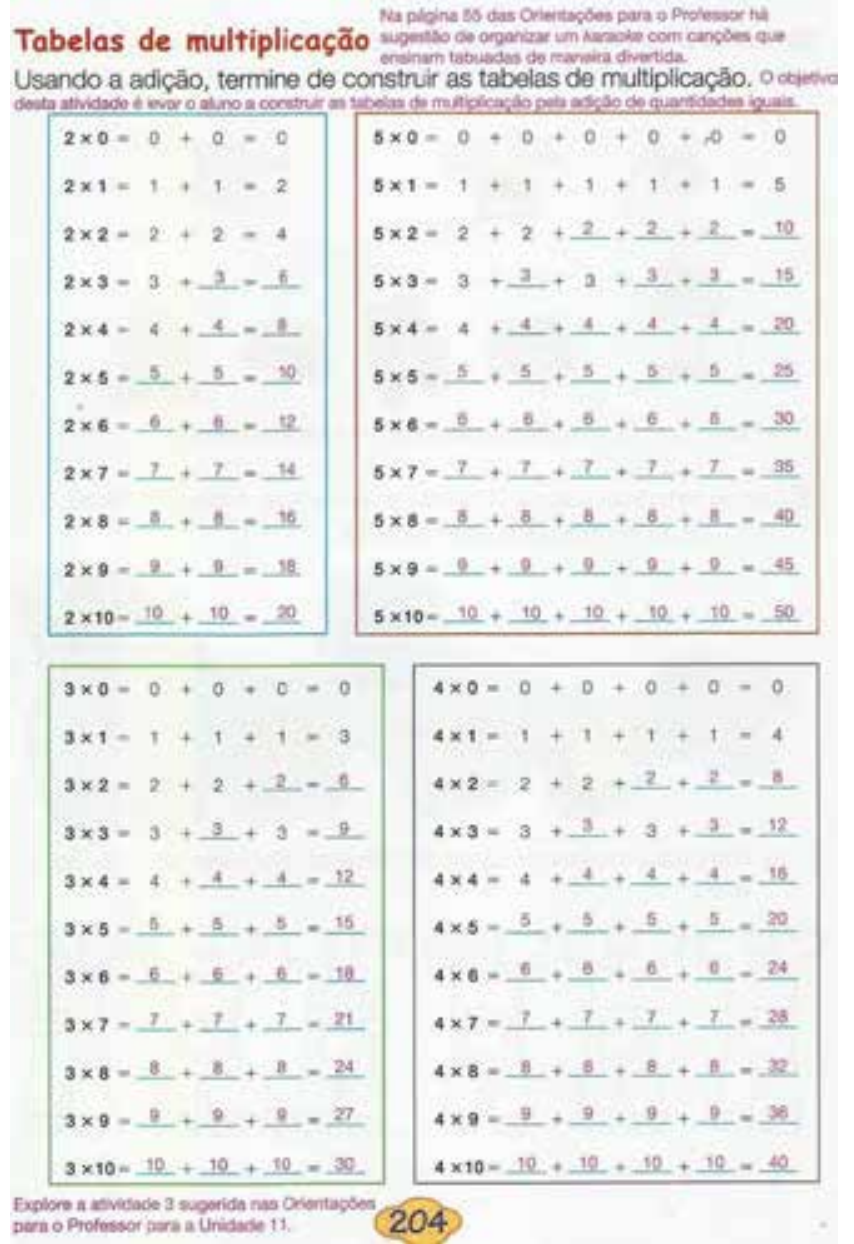

Fonte: Centurión et al. (2011, p. 204).

Há uma variedade de multiplicações, cuja ideia central e resultado da operação fixaram-se na soma de parcelas iguais. As quantidades a serem operadas são de dois (2) em dois, três (3) em três, quatro (4) em quatro e de cinco (5) em cinco. A análise da situação em referência possibilita revelar algumas características, tais como: soma de quantidades iguais; o resultado das tabelas de multiplicação por dois (2) e por quatro (4) são números pares; a tabela de multiplicação por três (3) apresenta número par intercalado por número ímpar como resultado; todos os resultados são números terminados em zero (0) ou cinco (5), sucessivamente, na tabela de multiplicação por cinco (5).

Porém, vale destacar que, dentre as várias características há uma principal comum a 
todas as tabelas, a soma de quantidades iguais que segue um padrão: o multiplicando indica quantas vezes o multiplicador deve ser adicionado. Além disto, em cada tabela, o multiplicando é um valor fixo, na tabuada do número dois, o multiplicando é o número dois, na tabuada do número três, é o número três, e assim sucessivamente. Assim, conforme preveem os princípios da lógica formal, cria-se uma representação geral, que é válida para todas as tabuadas, mas apenas com base na aparência externa, sem revelar sua conexão interna, que dá origem às diferentes tabuadas.

Na primeira tabela de multiplicação obtêm-se os resultados por meio da soma de duas (2) parcelas iguais $(0+0,1+1,2+2,3+3, \ldots, 10+10)$. Na tabuada do número cinco, a essência continua a mesma, no entanto, difere na quantidade de parcelas a serem adicionadas. $O$ resultado de cada operação é obtido por meio da adição de cinco (5) parcelas iguais $(0+0+0+0+0,1+1+1+1+1,2+2+2+2+2, \ldots, 10+10+10+10$ $+10)$. Procedimento análogo ocorre nos demais quadros.

A lógica formal tradicional não considera o caráter contraditório do geral e particular, aborda o conceito apenas como um conjunto de atributos. A relação entre o geral e o particular é examinada somente sob o ponto de vista de quais são as características, as propriedades inerentes a um conceito e quais são inerentes a outro. "Para a lógica formal não é importante a dialética do geral e do particular, do nexo, da passagem de um para o outro, mas sua diferença, sua separação" (Rosental, 1962, p. 238).

Deste modo, a lógica formal atua com conceitos inertes, e não considera os processos de desenvolvimento e mudanças. Assim, de acordo com Davýdov (1982), revela sua debilidade de princípios e sua inaplicabilidade para a interpretação nos processos de generalização e formação de conceitos científicos. Carece de critérios para associar os objetos em grupos, nos quais estão interligados por meio das relações internas, pela essência e não apenas pela aparência externa.

Nos limites da lógica formal tradicional, o concreto é concebido como o objeto mesmo, o singular, passível de observação por meio dos órgãos dos sentidos. O abstrato, por sua vez, é entendido como o geral. Assim, o geral "atua na imagem sensorial-concreta sob forma empírica, como semelhante, único para uma série de objetos" (Kopnin, 1978, p. 158). Então, o pensamento consiste, de um lado, no trânsito do sensorial concreto e singular, entendido como "objeto solto sensorialmente perceptível ou sua imagem gráfica [...]" para o mental abstrato e formalmente geral (Davýdov, 1982, 332). Por outro lado, na transição inversa, do abstrato para o sensorial-concreto, ocorre o desprendimento da identificação de certos objetos singulares como pertencentes a uma classe dada, ou seja, o geral.

Esse movimento de formação do conceito empírico segue do particular para o geral. O produto é resultado da comparação de objetos singulares. Portanto, o geral surge como resultado da ascensão do sensorial concreto ao abstrato mental, expresso na palavra. O nível de abstração é medido pela quantidade e variedade de objetos que constituem uma determinada classe. Quanto mais alto o nível de generalização, mais 
abstrato e teórico será o pensamento.

Esse movimento conceitual empírico requer que o ensino de matemática seja organizado da aritmética para a álgebra. O foco nos primeiros anos escolares incide em uma parte menos abstrata: a aritmética, como as situações anteriormente analisadas. O foco era para as necessidades de contagem e operacionalização nos limites dos números naturais, a partir de grandezas discretas.

De acordo com Davídov (1987), os programas do ensino tradicional são elaborados em consonância com a capacidade dos estudantes, determinada pela psicologia tradicional, para cada faixa etária. Deste modo, a aprendizagem ocorre quando a criança atinge maturação biológica.

A psicologia tradicional supõe que uma criança, em idade escolar regular e que frequenta o primeiro ano escolar, não está psicologicamente desenvolvida para aprender conteúdos relacionados à álgebra, em função do seu alto nível de abstração. Então, nos primeiros anos da educação básica, o ensino de matemática é limitado à aritmética. A álgebra fica relegada aos anos seguintes.

Porém, estudos realizados por neurologistas e psicólogos demonstram que o "pensamento lógico inicia seu desenvolvimento a partir dos 6 anos" de idade (Ilienkov, 2006, p. 53). A idade escolar inicial é ideal para a criança receber "informação e socialização adequada, depois é mais difícil adquiri-la, apesar da capacidade e plasticidade do cérebro" (Ilienkov, 2006, p. 53).

Ao conceber o pensamento em desenvolvimento, Vigotski (2000) afirma que a aprendizagem da álgebra contribui para uma compreensão mais profunda da aritmética. E em complemento, Davýdov (1987) afirma que a aprendizagem reduzida à aritmética limita a compreensão posterior dos conceitos matemáticos. $O$ ensino tradicional obstaculiza a aprendizagem de conceitos propriamente científicos e não contribui para a elaboração de um pensamento sistemático, organizado e profundo. Esse ensino é insuficiente para o desenvolvimento do pensamento teórico (Davýdov, 1982).

Vale ressaltar que a presença dos fundamentos da lógica formal não é uma exclusividade da proposição em análise. A corrente empírica persiste, atualmente, de acordo com Fiorentini e Lorenzato (2006), tanto em livros didáticos de matemática quanto no ideário de muitos professores da referida disciplina.

Com o intuito de oferecer subsídios teórico-metodológicos para repensar algumas proposições brasileiras, na próxima seção apresentamos a proposição davydoviana para introdução da tabuada. 


\section{Introdução da tabuada na proposição davydoviana}

Davýdov (1982) propôs um novo modo de organização do ensino, com base nos fundamentos da lógica dialética, ao entender que o pensamento teórico supera, por incorporação o pensamento empírico. Juntamente com colaboradores Davýdov (1982) elaborou e desenvolveu em caráter investigativo, uma proposição para o Ensino de Matemática. A partir dos resultados de investigações em sala de aula, o grupo publicou livros didáticos e manuais de orientação ao professor. Este material constitui a fonte de dados referentes à proposição davydoviana extraída da versão original do livro didático do segundo ano do ensino fundamental. Resolvemos as situações apresentadas no livro didático com base no manual de orientação ao professor (Gorbov, Mikulina \& Savieliev, 2009) e, posteriormente, procedemos à análise.

O conteúdo e a metodologia de ensino da proposição davydoviana expressam um conjunto de princípios da teoria histórico-cultural válidos para todas as disciplinas do currículo escolar. Além disto, é importante esclarecer que a tabuada é somente uma parte de um sistema integral, correspondente a uma única disciplina, a matemática. Portanto, em termos de desenvolvimento do pensamento teórico, há que se considerar o caráter mais amplo desta proposta. Isto por que somente um conceito isolado não resolve o problema do desenvolvimento do tal pensamento em sua totalidade. Tratase de um recorte para efeito de pesquisa. Vale ressaltar também, a necessidade de repensar uma das finalidades da educação pré-escolar de preparar a criança para a atividade de estudo. Sem esta educação adequada não é possível desenvolver a proposição davydoviana no ensino fundamental brasileiro.

Diferentemente da proposição brasileira anteriormente analisada, que prima pela representação direta de grandezas discretas, na proposição davydoviana, os conceitos são desenvolvidos a partir da relação entre medidas de grandezas, não só discretas, também contínuas. As grandezas são as propriedades dos objetos que permitem determinar seu tamanho: maior, menor, igual, mais, menos..., enfim, sua medida.

$\mathrm{Na}$ especificidade do conceito de multiplicação, conceito-base para a tabuada, os elementos que constituem a relação universal surgem a partir da necessidade de determinar a medida de uma grandeza consideravelmente maior que a unidade de medida disponível. Nestes casos, a utilização direta da unidade de medida é caracterizada como trabalhosa, conforme a situação a seguir, que requer a medição da superfície de medida $A$ com a unidade de medida $E$ (Ilustração 3). 
Ilustração 3 - Introdução da necessidade da unidade de medida intermediária
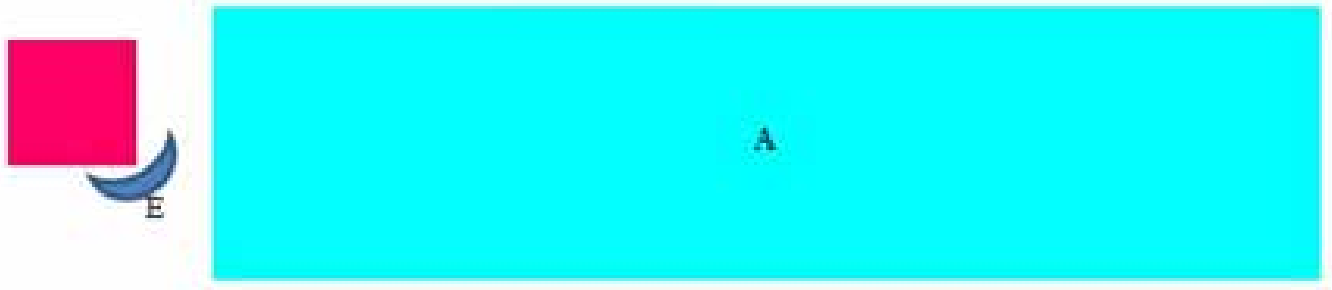

E

\section{A}

Fonte: Elaboração nossa com base em Davýdov et al. (2012).

Durante o desenvolvimento da situação (Ilustração 3), o professor conduz as reflexões de modo que os estudantes concluam que será um processo muito demorado medir toda a superfície de medida A com unidade de Medida E. E que sintam a necessidade de construir uma nova unidade de medida, a partir da medida inicial (E), para agilizar o processo de medição de A. Em outras palavras, é necessário construir, a partir da medida inicial (E), outra unidade de medida com tamanho intermediário entre $A$ e E. A orientação davydoviana é que esta nova unidade de medida não seja dada, mas construída pelos estudantes, sempre com acompanhamento do professor. A llustração 4 mostra uma possível unidade de medida intermediária $(P)$ e, com ela, a determinação do resultado da medição em relação a $\mathrm{E}$.

Ilustração 4 - Introdução da unidade de medida intermediária P = 2E
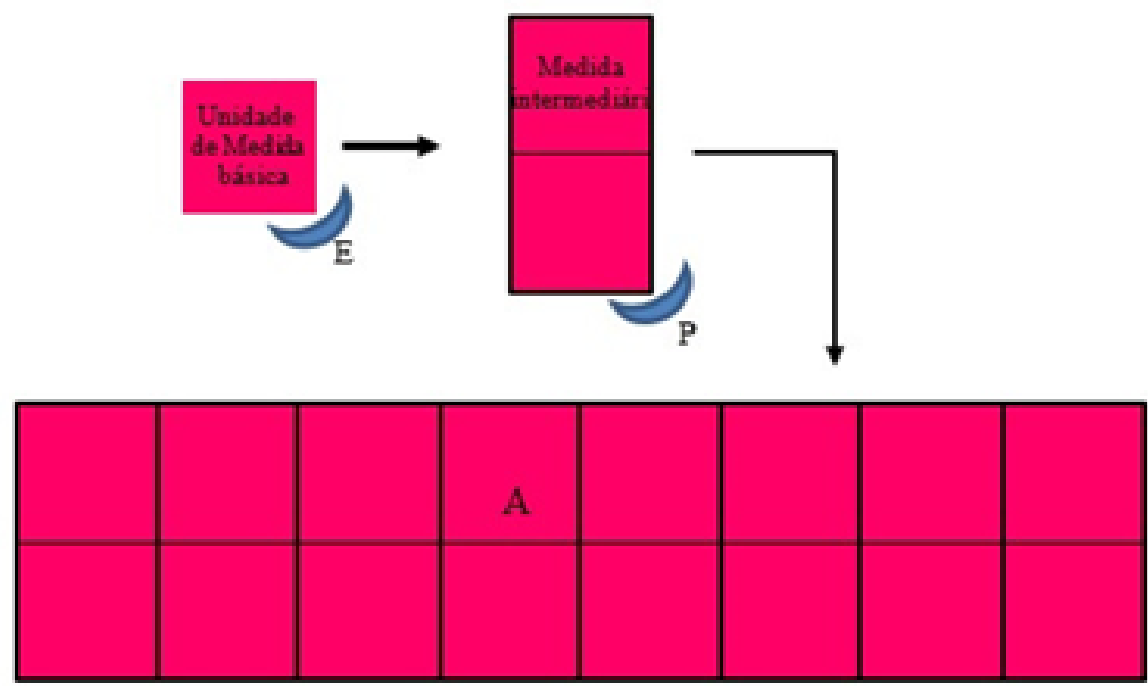

Fonte: Elaboração nossa com base em Davýdov et al. (2012). 
A conclusão a ser obtida, com o direcionamento do professor, é que a unidade de medida maior $(P)$ é menos trabalhosa para determinar de quantas vezes ela se repete em $A$. Esta é constituída por 8 unidades intermediárias $(A=8 P)$. Entretanto, $A$ é igual a quantos $E$ ? Sabemos que $P=2 E$. Assim, temos: $2 \times 1=2 ; 2 \times 2=4 ; 2 \times 3=6 ; 2 \times 4=8 ; 2$ $\times 5=10 ; 2 \times 6=12 ; 2 \times 7=14 ; 2 \times 8=16$. Portanto, a unidade de medida $E$ repete-se 16 vezes em $A(A=16 E)$. O primeiro número ou termo (2) de cada sentença é denominado multiplicando; e o segundo (1, 2, 3, 4, 5, 6, 7 e 8), multiplicador.

Assim, em uma única tarefa são contempladas significações algébricas (representação dos valores desconhecidos por meio de letras); geométricas (relação entre as medidas de área); e aritméticas (quantidade de vezes que as unidades de medida se repetem), diferentemente da proposição anterior, cujo foco incidia na significação aritmética como resultante da representação direta de quantidades.

Os elementos que constituem a essência aqui, não consistem nas características comuns que se repetem. Então, quais são os elementos que constituem a relação essencial, universal, do conceito de multiplicação? Os elementos são: unidade de medida básica, unidade de medida intermediária e o resultado da medição. $\mathrm{Na}$ proposição davydoviana, estes elementos são revelados durante o experimento objetal de medição de várias grandezas, como volume, massa, capacidade, comprimento, entre outras. Gradativamente, a relação entre esses elementos (relação de multiplicidade), que dá origem às diversas tabuadas, é abstraída com o auxílio da reta numérica, conforme segue.

Qual é o resultado de dois vezes um ? (2 x 1 = ?). Do ponto de vista da matemática, dois tomados por uma vez. Na reta numérica, esta relação é representada por um agrupamento composto por duas unidades. Cada agrupamento é delimitado por um arco, conforme a llustração 5 , que mostra a representação, na reta numérica, de $2 \mathrm{x}$ $1=2$ e $2 \times 2=4$.

Ilustração 5 - Representação na reta numérica de $2 \times 1=2$ e $2 \times 2=4$

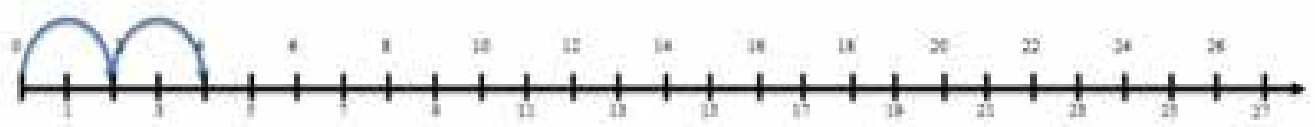

Fonte: Elaboração nossa com base em Davýdov et al. (2012).

Para registrar dois vezes dois, fazem-se dois arcos constituídos de duas unidades cada. O próximo registro, $2 \times 3$ (dois tomados por três vezes), também tem seu produto determinado com o auxílio da reta numérica, de acordo com a llustração 6, que mostra a Tarefa 1 , representação na reta numérica de $2 \times 3=6$. 
Ilustração 6 - Representação na reta numérica de 2 × 3 = 6

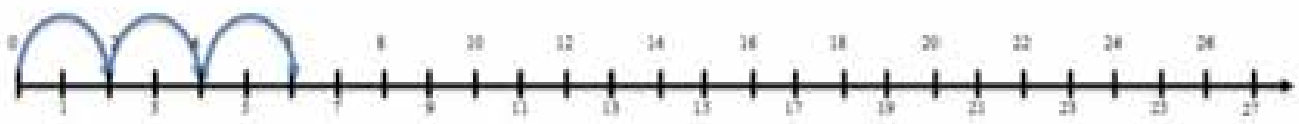

Fonte: Elaboração nossa com base em Davýdov et al. (2012)

Essa reflexão é realizada a partir da articulação entre a representação objetal (Ilustração 4) e a representação gráfica (Ilustração 7). A reta numérica constitui a existência mediatizada do processo de medição realizado no plano objetal. Em outras palavras, na reta se reproduziu, abstratamente, o experimento objetal realizado durante a medição da área (Ilustração 4). Em outras palavras, a lógica interna, a essência da tabuada, foi revelada no experimento real de medição e abstraída na reta numérica, por meio do procedimento de redução do concreto ao abstrato. Os demais resultados da tabuada do número dois são determinados por procedimento análogo ao anterior (Ilustração 7).

Ilustração 7 - Sistematização da tabuada do número dois na reta numérica
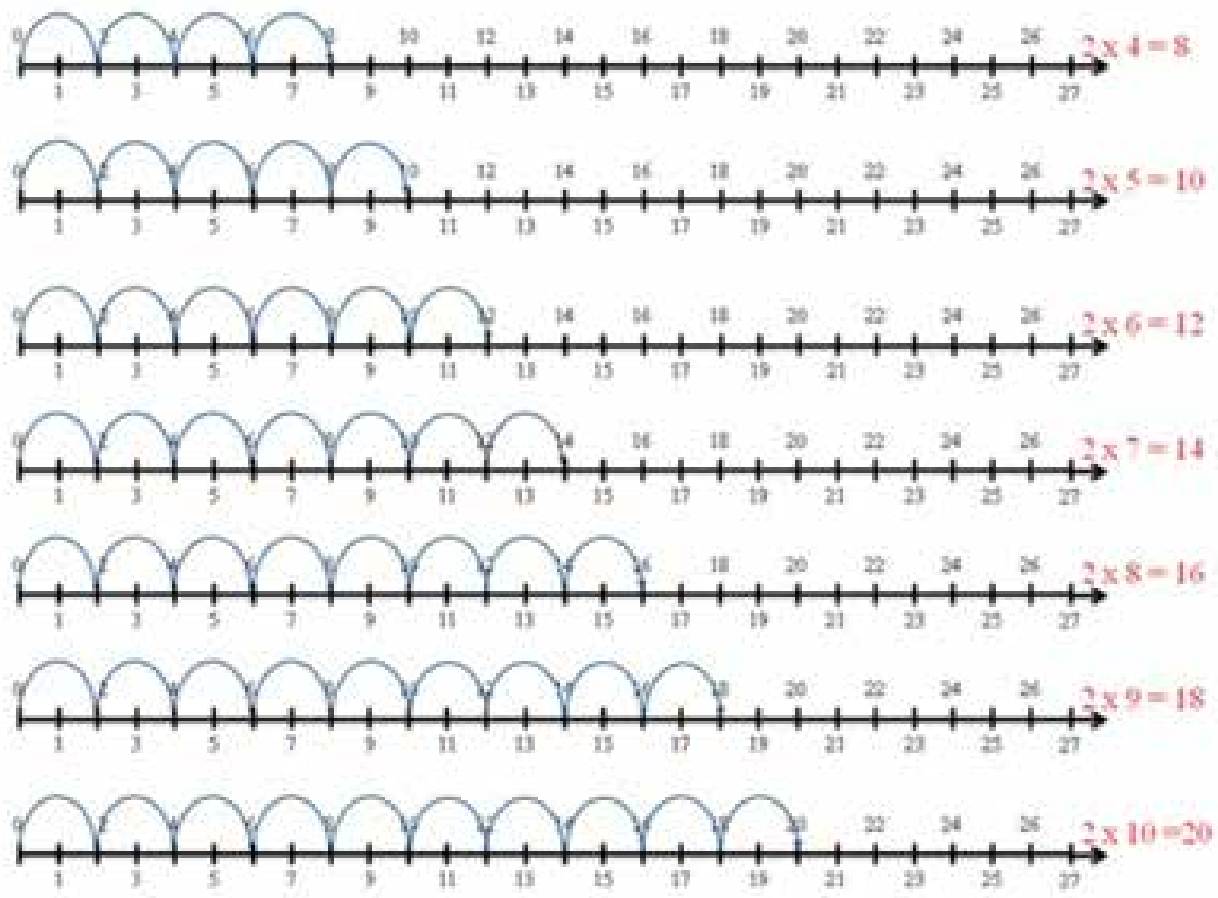

Fonte: Elaboração nossa com base em Davýdov et al. (2012). 
Ainda, concomitantemente, a tabuada do número dois é sintetizada e registrada, conforme a llustração 8.

Ilustração 8 - Síntese da sistematização da tabuada do número dois (2)

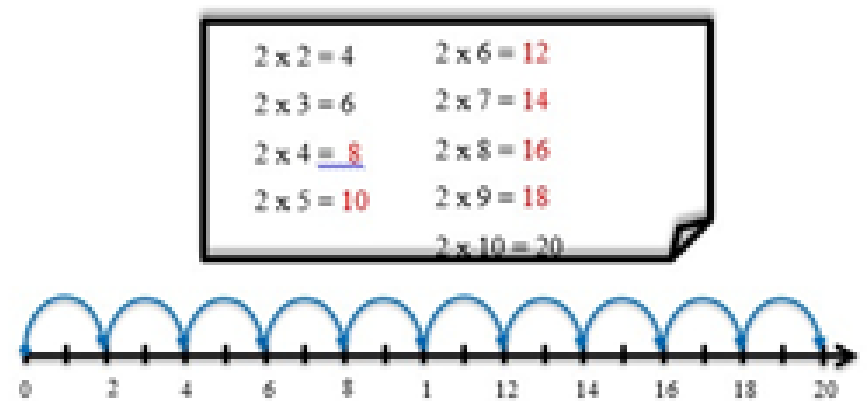

Fonte: Elaboração nossa com base em Davýdov et al. (2012).

O processo não se encerra em $2 \times 10=20$, a sequência é infinita. Ela não pode ser representada no plano objetal, mas é totalmente acessível ao experimento mental após a revelação de sua essência teórica. Qual o resultado de dois vezes onze? E dois vezes doze? Enfim, a partir da lógica interna de constituição da tabuada, revelada no plano objetal e abstraída na reta numérica, pode-se refletir sobre sua continuidade, já em nível de concreto pensando.

A lógica interna de constituição da tabuada foi modelada nas formas objetal e gráfica, no movimento de redução do concreto ao abstrato. Quando a lei abstraída possibilita a continuidade da sequência da tabuada, independentemente da representação objetal ou gráfica, no plano mental, trata-se da ascensão do abstrato ao concreto pensado.

Neste movimento, revela-se o caráter essencial como base da unidade interna do sistema integral no processo de generalização, na identificação das conexões sujeitas à lei. A reta numérica é um dos elementos mediadores utilizados na proposição davydoviana para a elevação da relação essencial, revelada no plano objetal, ao plano mental.

A abstração é o processo em que se reflete a essência, a lei das coisas (llienkov, 2006). Neste sentido, a abstração incide no pensar sobre a essência, sobre a relação interna que, no exemplo em análise, consiste em um valor fixo: dois (2) para a tabuada do número dois (2); três (3) para a tabuada do número três (3), e assim sucessivamente. São conexões objetivas que asseguram a unidade entre todas as tabuadas e, portanto, passíveis de generalização.

A partir da generalização inicial, também denominada por Davídov (1988) de substancial, revelam-se as inter-relações entre o singular, particular e universal. 
O elo entre o universal e o singular é o particular nas regularidades apresentadas anteriormente. O particular consiste na unidade de medida intermediária. Com a variação da unidade de medida intermediária, obtemos as diferentes tabuadas particulares: na tabuada do número dois, a medida intermediária é o dois e, portanto, é o dois que se repete; na tabuada do número três, a medida intermediária é o três e, logo, é o três que se repete, e assim infinitamente. Assim, obtemos as diferentes singularidades para cada tabuada particular, ao manter a unidade de medida intermediária fixa e variar a quantidade de vezes que ela se repete.

Tomemos, como exemplo, uma particularidade, a tabuada do número três (3), e ao variar a quantidade de vezes que a unidade de medida intermediária (3) se repete obteremos as seguintes singularidades: $3 \times 1=3 ; 3 \times 2=6 ; 3 \times 3=9, \ldots$ Assim, a tabuada particular, do número três (3), surge no movimento entre o universal (relação entre a unidade básica, intermediária e total), particular e singular.

É importante ressaltar que, na proposição davydoviana, a tabuada emerge de um longo percurso, permeado por sucessivas abstrações e generalizações. Assim como uma rede é construída e mantida por meio dos inúmeros nós que unem e entrelaçam todas as suas partes, "os conceitos da ciência são os nós que conectam em uma unidade todos os seus juízos e conclusões, tornando possível a existência da própria ciência" (Rosental, 1962, p. 232). Sendo assim, o que seria do conceito de tabuada sem os conceitos de número, multiplicação, adição, grandezas, unidades de medida, entre outros? Cada um desses conceitos expressam

conhecimentos obtidos como resultado de um longo desenvolvimento da ciência e do saber prático do homm. Cada um deles constitui uma generalização comprimida, concentrada de tais conhecimentos e experiências. Se pudermos emitir pensamentos sobre tais ou quais fenômenos e processos são, precisamente, porque temos em nossa disposição essas "células", de que está formando todo o "organismo" do conhecer (Rosental, 1962, p. 230, grifos do autor).

Dito com outras palavras, cada um dos conceitos (número, multiplicação, adição, unidades de medida...) que constitui o sistema conceitual, no qual se insere a tabuada, é sistematizado na proposição davydoviana de ensino como resultado do desenvolvimento de várias tarefas particulares. Aos interessados em aprofundálas, indicamos a leitura de produções desenvolvidas por vários grupos de pesquisas brasileiros, dentre eles, o Grupo de Pesquisa Teoria do Ensino Desenvolvimental na Educação Matemática (TedMat/UNISUL) e o Grupo de Pesquisa em Educação Matemática: uma Abordagem Histórico-Cultural (GPEMAHC/UNESC), que têm se debruçado com afinco na proposição davydoviana para o ensino de matemática. 


\section{Considerações finais}

Investigamos a sistematização da tabuada apresentada em dois livros didáticos do segundo ano do ensino fundamental, um brasileiro e outro russo. Um correspondente à coleção de livros didáticos de matemática mais utilizada por professores das escolas estaduais dos municípios constituintes da extinta $36^{\text {a }}$ Gerência Regional de Educação - Braço do Norte/SC (Hobold, 2014), e o outro oriundo da coleção publicada por Davýdov e colaboradores (2009).

Ao proporem a sistematização da tabuada, as duas proposições seguem movimentos distintos. Na brasileira, a tabuada surge a partir da observação das quantidades que constituem os agrupamentos. Por decorrência deste ponto de partida, surgem a abstração e a generalização empírica. Trata-se do que é comum a todos os exemplos: sempre que houver dois (2) agrupamentos compostos por cinco (5) objetos cada, o resultado será 10. Os objetos podem ser os mais variados possíveis (peteca, tampinhas, palitos, dedos...). É uma imagem ideal do objeto material nos limites da grandeza discreta e das significações aritméticas. Não há um elemento mediador, de caráter geral, que possibilite essa abstração, como a reta numérica, por exemplo. Nesse caso, a tabuada desenvolvida a partir da representação direta dos objetos torna-se empírica. Isto porque a essência conceitual resulta da aparência externa dos agrupamentos, carente de análise das relações que geram sua lógica interna.

Na proposição davydoviana, por sua vez, o ensino da tabuada contempla a inter-relação das significações aritméticas, algébricas e geométricas no movimento que envolve o geral, universal, particular e singular, a partir das relações de medidas de grandezas discretas e contínuas.

Inicialmente, os valores das medidas são desconhecidos e representados na sua forma geral, por meio de uma letra. Para cada conceito há uma conexão interna, que implica na análise da relação entre o universal, singular e particular. É por meio desta relação que o universal se manifesta em forma de lei.

Por outro lado, o ponto de partida, nos limites das grandezas discretas, reduz o pensamento matemático ao campo dos números inteiros positivos. $O$ conceito de número resulta como sinônimo do conceito de contagem. Enquanto a inclusão, também, da relação entre medidas de grandezas contínuas, a partir da medição, contempla o contexto matemático que, mais tarde, subsidiará a sistematização dos demais campos numéricos, para além dos inteiros positivos. Outra consequência importante refere-se às significações contempladas. Entendemos que conceitos matemáticos são constituídos por significações aritméticas, algébricas e geométricas. Portanto, abordar apenas a aritmética implica em considerar apenas um fragmento deste conhecimento.

Enfim, uma proposição considera o pensamento empírico e a outra, por incorporação 
deste, a supera e abarca o pensamento teórico. Isto não significa que o pensamento empírico é ponto de partida para o desenvolvimento do pensamento teórico, na proposição davydoviana. Ao contrário, de acordo com Davýdov (1982), o pensamento empírico obstaculiza o pensamento teórico. Por isso, desde o ponto de partida, desde o experimento objetal, a referência é para a revelação dos elementos teóricos que constituem a relação universal e sua posterior modelação, tanto por meio das próprias grandezas, durante a medição, quanto no plano abstrato, no contexto da reta numérica.

Diante de tais resultados, algumas questões emergem e poderão desencadear novas investigações, tais como: por que a coleção brasileira em análise é adotada em uma rede de ensino que preconiza, em sua proposta curricular, o desenvolvimento do pensamento teórico a partir dos fundamentos da teoria histórico-cultural? Existem livros didáticos brasileiros fundamentados na referida teoria? É possível implementá-la no sistema educacional brasileiro, considerando o atual contexto econômico, político e social? Quais os entraves?

\section{Referências}

Centurión, M. et al. (2011). Porta Aberta: alfabetização matemática, São Paulo: FTD. Davýdov, V. V. (1982). Tipos de generalización en la enseñanza. 3.ed. Habana: Pueblo y Educación.

Davídov, V. V. (1988). La enseñanza escolar y el desarrollo psíquico: investigación teórica y experimental. Trad.: Marta Shuare. Moscú: Progreso.

Davídov, V. V. (1987). Análisis de los principios didácticos de la escuela tradicional y posibles principios de enseñanza en el futuro próximo. In: Shuare, M. La psicología Evolutiva y pedagógica en la URSS. Moscú: Progreso.

Davýdov, V. V. et al. (2012). Matemática. $2^{\circ}$ ano: livro didático e de exercícios para os estudantes. 3. ed. Tradução de Ediséia Suethe Faust Hobold e Josélia Euzébio da Rosa. Moscú: Vita- Press. [Tradução realizada para fins de pesquisa].

Fiorentini, D. \& Lorenzato, S. (2006). Investigações em Educação Matemática: percursos teóricos e metodológicos. Campinas: Autores Associados.

Hobold, E. S. F. (2015). Proposições para o ensino da tabuada com base nas lógicas formal e dialética. 2014. 199 f. Dissertação (Mestrado em Educação) - Universidade do Sul de Santa Catarina, Tubarão. Recuperado em 20 de janeiro de 2015, de ttps:// 
aplicacoes.unisul.br/pergamum/pdf/108492_Ediseia.pdf>.

Hobold, E. S. F.; Rosa, J. E. (2017). O ensino da tabuada no contexto das ações de estudo propostas por Davýdov e colaboradores (v. 22, p. 1-30). Revista Brasileira de Educação.

Ilienkov, E. V. (2006). La ascensión de lo abstracto a lo concreto en principios de la lógica dialéctica. In: Alfredo Tecla Jiménez, Teoría de la construcción del objeto de estudio (p. 151-200). México: Instituto Politécnico Nacional.

Kopnin, P. V. (1978). A dialética como lógica e teoria do conhecimento. Rio de Janeiro: Civilização Brasileira.

Kosik, K. . (1995). Dialética do concreto. 2. Ed. Rio de Janeiro: Eitora Paz e Terra.

Lefebvre, H. (1991). Lógica Formal e Lógica Dialética. Trad.: Carlos Nelson Coutinho. 5.ed. Rio de Janeiro: Civilização Brasileira.

Libâneo, J.C. \& Freitas, R. A. M. M. (2013). Vasily Vasilyevich Davydov: A escola e a formação do pensamento teórico- científico. In: Longarezi, A. M.; Puentes, R. V. (orgs.). O Ensino desenvolvimental: vida, pensamento e obra dos principais representantes russos (p. 315- 350). Uberlândia: EDUFU.

Rosa, J. E. (2012). Proposições de Davydov para o ensino de matemática no primeiro ano escolar: inter-relações dos sistemas de significações numéricas. 2012. 244 f. (Tese de Doutoramento em Educação). Área de concentração: Educação Matemática. Universidade Federal do Paraná, Curitiba.

Rosental, M. M. (1962). Princípios de Logica Dialectica. Trad.: Augusto Vidal Boget. Uruguai: Montevidéu: Pueblos Unidos S.A.

Rosental, M. M. (1960). Lo histórico y lo lógico. In: Rosental, M. M., Straks, G. M. Categorías del Materialismo Dialéctico (p. 324 - 351). Trad.: Adolfo Sanchez Vazquez e Wenceslao Roces. México: Grijalbo S.A.

Triviños, A. N.S. (1987). Introdução à pesquisa em ciências sociais a pesquisa qualitativa em educação. São Paulo: Atlas.

Vigotski, L. S. (2000). A construção do pensamento e da linguagem. Trad.: Paulo Bezerra. São Paulo: Martins Fontes.

Gorbov, S. F.; Mikulina, G. G.(2009). Ensino de matemática. $2^{\circ}$ ano: livro do professor do ensino fundamental. 3. ed. Tradução de Elvira Kim. Moscú: Vita-Press. [Tradução realizada para fins de pesquisa]. 